\title{
An Alternate Technique for Precise Transfer of Information from the Provisional to Definitive Full-mouth Restorations
}

\author{
Amar Bhochhibhoya
}

\begin{abstract}
Aim and objective: This technique aims to demonstrate a practicable approach for the precise transfer of information from the provisional to the final full-mouth restorations.

Background: The prosthetic rehabilitation of severely worn dentition often poses challenges to the dental practitioners as it necessitates several stages of treatment sequencing including multiple sets of provisional restorations, which require several adjustments over a reasonable period of time to establish the desired esthetics and functions. Provisional restorations help to visualize and communicate the treatment outcomes to the patient and the dental technician. The patient-specific information reflected in the provisional restorations should not be lost during the clinical procedures and must be accurately adapted to the definitive restorations.

Technique:The method presented in this article is a variation of the "cross-mounting" procedure. The technique demonstrates the use of anterior composite index stabilized cross-mounting and putty matrix, which facilitates the design and fabrication of the metal framework and evaluates the available restorative space for the final prosthesis.

Conclusion: This technique allows the restorative dentist to duplicate the prosthetic information gained from provisional restorations accurately in the final restorations, ensures better and accurate mounting, and allows verification of the centric relation before investing time in the fabrication of the definitive restorations.

Keywords: Composite index, Concepts/philosophies, Cross-mounting, Full-mouth rehabilitation, Gnathology, Occlusion, Provisional restorations, Putty matrix.

International Journal of Prosthodontics and Restorative Dentistry (2021): 10.5005/jp-journals-10019-1310
\end{abstract}

\section{INTRODUCTION}

Gradual tooth wear is a physiological process that occurs during the lifetime of a patient, triggering an enamel loss of approximately 28-30 $\mu \mathrm{m} / a n n u m .{ }^{1,2}$ Accentuated tooth wear is commonly linked to the combination of mechanical and chemical processes which mainly includes deleterious dietary habits, bruxism, and parafunctional activities. ${ }^{3-5}$ Excessive tooth wear can cause serious damage to occlusal harmony resulting in impaired oral functions and esthetics. ${ }^{6-8}$

Appropriate restorative approaches, understanding of longterm restorative success, risk assessment, and patient compliance reinforce the overall success of the treatment. ${ }^{9,10}$ To fabricate successful prostheses, it is essential to provide the laboratory with the registration of an accurate interocclusal relationship, adequate vertical dimension (VD), and the orientation of the occlusal plane. ${ }^{11}$ Provisional restorations are often fabricated from the templates made on the diagnostic wax-up which are used for evaluation of acceptance of a specific treatment modality. ${ }^{12}$ Complex rehabilitations can be a time and labor-intensive process which requires the fabrication of multiple sets of provisional restorations until desired results are achieved. ${ }^{13}$ Accurate duplication of this information in the final prosthesis is the key to the predictable treatment outcomes.

Currently, a range of techniques have been proposed to transfer the prosthetic information from the fixed provisional prosthesis. ${ }^{14}$ Chaimattayompol et al. described cross-mounting buccal index to help transfer the spatial relationships. ${ }^{15}$ Venezia et al. discussed digital cross-mounting for the same purpose. ${ }^{16} \mathrm{Joo}$ et al. recommended a digital technique involving double-scanning to superimpose an interim restoration and existing teeth. ${ }^{17}$ To the
Department of Prosthodontics, TU Dental Teaching Hospital, Maharajgunj Medical Campus, Institute of Medicine, Tribhuvan University, Kathmandu, Nepal

Corresponding Author: Amar Bhochhibhoya, Department of Prosthodontics, TU Dental Teaching Hospital, Maharajgunj Medical Campus, Institute of Medicine, Tribhuvan University, Kathmandu, Nepal, Phone: +977 9804320719, e-mail: amarbhochhibhoya@gmail. com

How to cite this article: Bhochhibhoya A. An Alternate Technique for Precise Transfer of Information from the Provisional to Definitive Fullmouth Restorations. Int J Prosthodont Restor Dent 2021;11(2):93-96.

Source of support: Nil

Conflict of interest: None

author's knowledge, there is a paucity of data regarding techniques that describe a synergistic combination of anterior composite index (ACl) stabilized cross-mounting and putty matrix for precise transfer of information from the provisional restoration to the final full-mouth restorations in a patient with severe teeth wear.

\section{TeChNique}

- Make impressions for diagnostic casts with irreversible hydrocolloid impression material (Zelgan; Dentsply Intl). Articulate the maxillary cast in a semi-adjustable articulator (Hanau Wide-Vue; Whip Mix) with a facebow transfer (Hanau Springbow; Whip Mix). Mount the mandibular cast with centric relation (CR) record using bite registration wax (Alu wax; Samit Products). 
- Evaluate interocclusal space at physiological rest position, the space was $6 \mathrm{~mm}$ in this patient. Intraoral examination revealed generalized wear of upper and lower dentition (Fig. 1). She exhibited an excessive amount of anterior speaking space, the anterior teeth appeared short, and the upper central incisors were not visible at rest. Evaluate the mounted diagnostic casts at the existing occlusal VD and raise the incisal pin of the articulator, based upon available interocclusal space at physiological rest. The pin was raised by $4 \mathrm{~mm}$ in this case to produce sufficient space for restoration. Perform the diagnostic wax-up of the working cast at the desired VD according to optimum esthetic and function.

- Prepare all the teeth and fabricate autopolymerizing acrylic resin (Tooth Molding Powder; DPI) provisional restorations using a vacuum-formed matrix (Vacuum Forming Material; Patterson Dental).

- Cement the provisional prosthesis with temporary cement (Temp-Bond; Kerr Dental). Adjust provisional restorations until anticipated results are achieved and evaluate the interim prosthesis for a period of 3 months for the patient's tolerance. An integral part of the whole rehabilitation process is restoring the anterior guidance. Fabricate a customized anterior guide table with the help of autopolymerizing acrylic resin to preserve and communicate anterior guidance to the technician.

- Obtain maxillary and mandibular definitive putty-wash impressions for prepared teeth with vinylpolysiloxane impression material (Elite HD+; Zhermack) to make definitive casts (Kalarock; Kalabhai). Make irreversible hydrocolloid impression of provisional restorations in the patient to fabricate the stone cast of temporary restorations. Make a face-bow record, and mount the stone cast (Kalstone; Kalabhai) of the maxillary provisional restoration in the articulator. Make CR record with bite registration wax and mount mandibular provisional cast. Train the patient to bite accurately on the posterior teeth, ensure correct bite with this CR position.

- Etch the palatal surface of provisional restorations on the maxillary central incisors with $37 \%$ phosphoric acid (Total etch; Vivadent) for 40 seconds and apply bonding agent (TE-Econom Bond; Vivadent) to the surface. Place bulk-fill composite restorative material (Tetric EvoCeram Bulk Fillon; Vivadent) on the etched surface. Ask the patient to close so that the incisal edge of mandibular incisors creates $\mathrm{ACl}$ when the jaw is closed

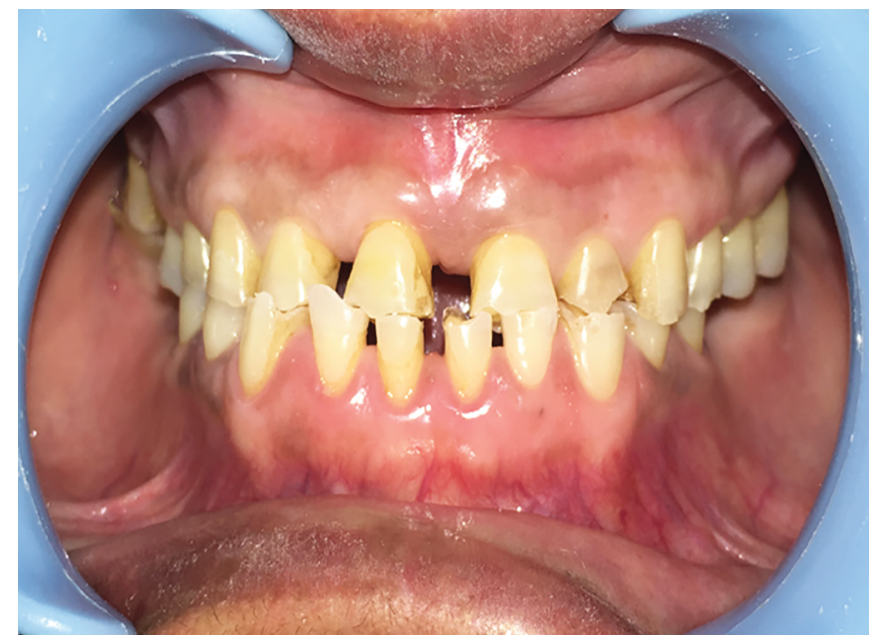

Fig. 1: Clinical presentation depicts severely worn dentition in CR position. Light cure the composite and train the patient to close into the $\mathrm{ACl}$ (Fig. 2).

- Remove the maxillary provisional restorations from posterior teeth. Soften the bite registration wax and ask the patient to occlude into the $\mathrm{ACl}$. Allow the wax to cool down and then remove the registration and store in chilled water (Record 1). Then, remove both the maxillary and mandibular provisionals from posterior teeth and make the bite record (Record 2).

- Reduce ACl with a bur, use shimstock foil (GMH; Hanel Medizina) to adjust anterior occlusal relationships.

- Use Record 1 to mount maxillary definitive cast against the stone cast of mandibular provisional restorations and use Record 2 to mount mandibular definitive cast against maxillary definitive cast (Fig. 3).

- Fabricate the silicon matrix for the stone casts of provisional restorations using vinyl polysiloxane putty impression material (Elite HD+; Zhermack). Adapt the material to cover the occlusal, buccal, and lingual aspects of the provisional stone casts and close the articulator. Maintain digital pressure until the putty material sets and remove it from the casts after it sets.

- Use the silicon matrix for designing and fabricating the metal frameworks. The matrix permits direct visualization of the amount of facial, lingual, and occlusal space available and aids in assuring that there is sufficient space for the veneering ceramic thickness to attain strength and structural durability (Fig. 4).

- Check the metal framework on definitive casts against the stone casts of provisional restoration for accessing available restorative space and also verify the position of the framework. Metal ceramic restorations were fabricated for anterior teeth and premolars and the posterior teeth were restored with cast metal restorations (Fig. 5).

\section{Discussion}

Widely diverse techniques exist concerning the successful management of patients with severe tooth wear which necessitates several phases of treatment including multiple sets of interim restorations. ${ }^{15,17-19}$ The prosthetic information gained from provisional restorations should be accurately duplicated in the final restorations. The options to transfer information have been discussed in the literature. ${ }^{16}$ The method presented in this article is a variation of the "cross-mounting" procedure which employs

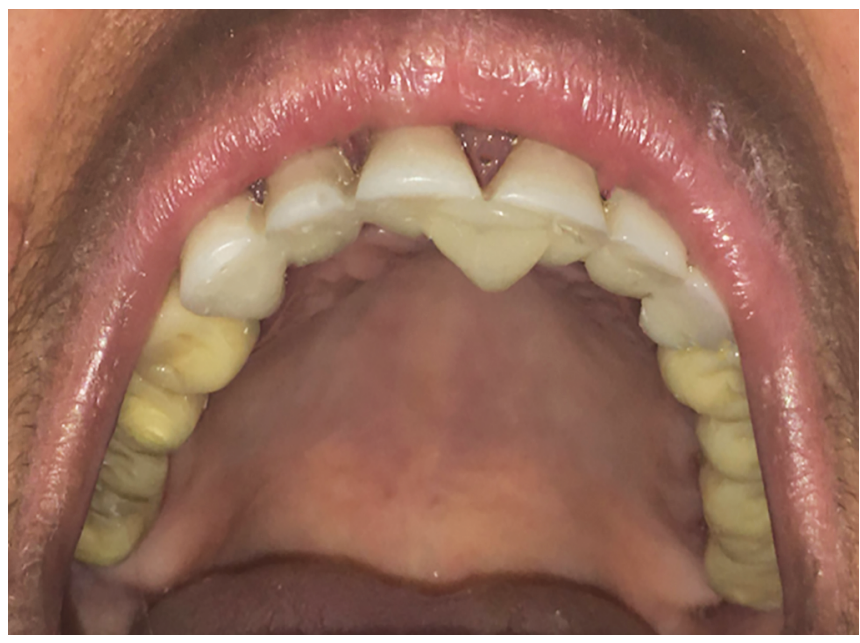

Fig. 2: Anterior composite index 


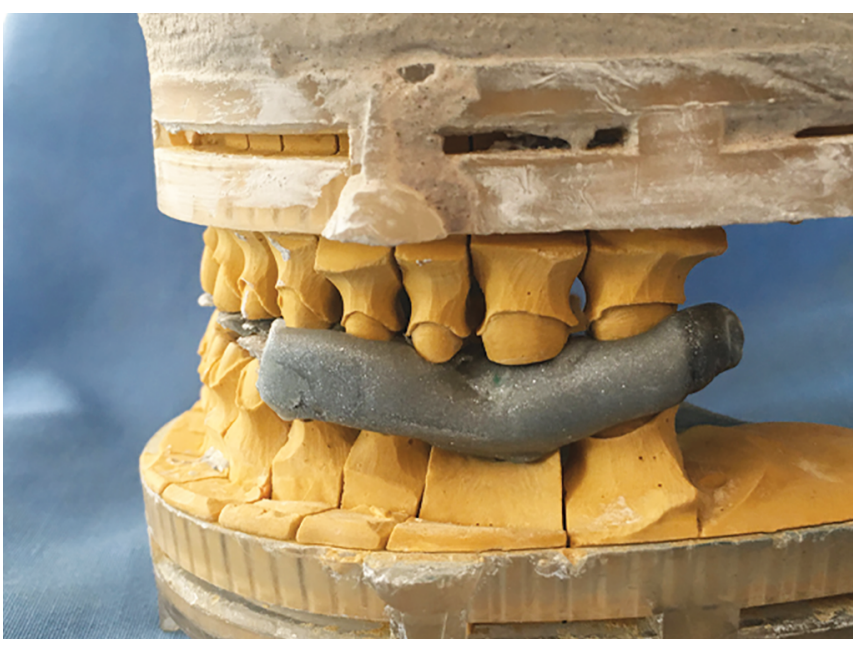

Fig. 3: Mounting of definitive maxillary and mandibular casts

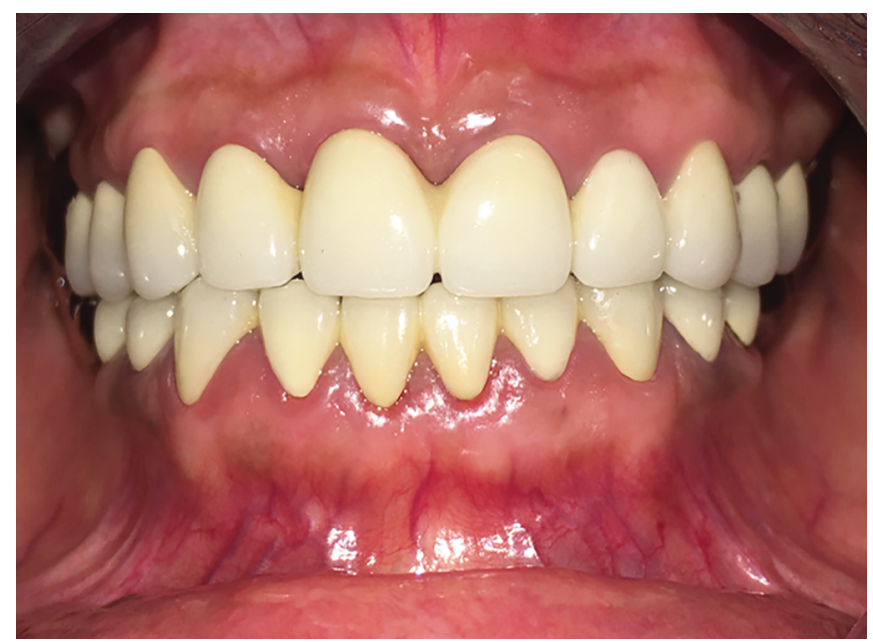

Fig. 5: Evaluation of final restorations

$\mathrm{ACl}$ to stabilize cross-mounting interocclusal registration and later, utilizes silicon matrix recorded on the provisional casts. Crossmounting allows mounting of two pairs of casts (both maxillary and mandibular casts of provisional restoration and definitive casts) on the same articulator at the same VD and with the same spatial relations. ${ }^{20}$

Accurate jaw closure to the $C R$ is crucial during cross-mounting registration procedures to precisely transfer the spatial relationship and the VD. ${ }^{21,22}$ When posterior provisionals are removed for bite registration, the guidance provided by intercuspation of provisional restorations are lost which makes it hard for the patient to occlude in the CR position. Precise closure to CR occurs only under a neuromuscularly relaxed and trained patient, or when a patient closes properly onto an anterior index. ${ }^{18}$ Anterior composite index guides the patient to consistently close in the same position which makes bite records much more predictable and reduces chances of errors in the registrations. It also helps to stabilize the bite during the setting of the bite registration material (Fig. 4). Every attempt should be made to avoid possible occlusal errors which reduce the frequency of occlusal adjustments. In absence of an anterior index, a lot of times patients may bite in a slight protrusive position without us detecting it. The anterior index also creates resistance

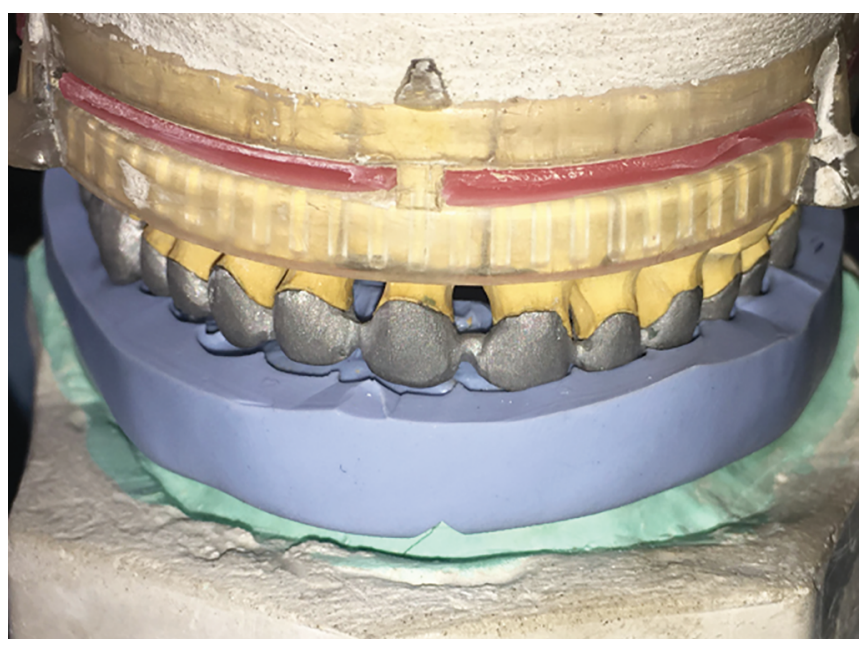

Fig. 4: Evaluation of maxillary metal framework with the help of putty matrix

and reverses the leverage of the mandible, creating a naturally braced tripod effect with the two condyles. ${ }^{23,24}$

Segmental removal of the provisional restorations and interocclusal registration to obtain indents of prepared teeth in relation to the opposing arch in $\mathrm{CR}$, not only ensures better and accurate mounting but most importantly ensures verification of the $\mathrm{CR}$ before investing time in fabrication of the definitive restorations.

This technique also employs silicon matrix recorded on the stone casts of provisional restorations which aid in 3D spatial visualization of the amount of restorative space and facilitate the design and fabrication of the metal framework for the final restorations.

This technique is not applicable in cases where anterior and posterior provisional restorations need to be splinted together. Other limitations include the long treatment period and effort required to produce diagnostic wax-up and multiple trial restorations and their associated expenses. This procedure also depends profoundly on the skill of the practitioner.

\section{Conclusion}

This paper demonstrates a practicable approach for the precise transfer of information from the provisional to the final full-mouth restorations with the use of $\mathrm{ACl}$ stabilized cross-mounting and putty matrix.

\section{References}

1. Alqahtani F. Full-mouth rehabilitation of severely worn dentition due to soda swishing: a clinical report. J Prosthodont 2014;23(1):50-57. DOI: 10.1111/jopr.12097.

2. Verrett RG. Analyzing the etiology of an extremely worn dentition. J Prosthodont 2001;10(4):224-233. DOI: 10.1111/j.1532849x.2001.00224.x.

3. Azouzi I, Kalghoum I, Hadyaoui D, et al. Principles and guidelines for managing tooth wear: a review. Int Med Care 2018;2:1-9.

4. Caga D, Lewis N. Treatment of tooth wear associated with reduced occlusal vertical dimension using direct composite restorations and a removable prosthesis. Prim Dent J 2021;10(1):120-125. DOI: $10.1177 / 2050168420980978$.

5. Joshi R, Gautam S, Joshi B. Assessment of tooth wear and its associated factors in adult patients visiting a dental hospital in 
Kathmandu. Nepal Nepal Med Coll J 2020;22(4):266-274. DOI: 10.3126/ nmcj.v22i4.34196.

6. Curtis JW, Farley BA, Goldstein RE. Abfraction, abrasion, attrition and erosion. Esthetics in Dentistry. 3rd ed., London: BC Decker Inc Hamilton; 2002. p. 501-523.

7. Song MY, Park JM, Park EJ. Full mouth rehabilitation of the patient with severely worn dentition: a case report. J Adv Prosthodont 2010;2(3):106-110. DOI: 10.4047/jap.2010.2.3.106.

8. Sun K, Wang W, Wang X, et al. Tooth wear: a cross-sectional investigation of the prevalence and risk factors in Beijing, China. BDJ Open 2017;3(1):16012. DOI: 10.1038/bdjopen.2016.12.

9. Goldman I. The goal of full mouth rehabilitation. J Prosthet Dent 1952;2(2):246-251. DOI: 10.1016/0022-3913(52)90051-6.

10. Meyers IA. Minimum intervention dentistry and the management of tooth wear in general practice. Australian Dent J 2013;58:60-65. DOI: 10.1111/adj.12050.

11. Goldstein R. Esthetics in dentistry. 1st ed., Philadelphia, PA: JB Lippincott; 1976. p. 387-388.

12. Hemmings KW, Howlett JA, Woodley $\mathrm{NJ}$, et al. Partial dentures for patients with advanced tooth wear. Dent Update 1995;22(2):52-59.

13. Rivera-Morales W, Mohl N. Restoration of the vertical dimension of occlusion in the everely worn dentition. Dent Clinic North Am 1992;36(3):651-664.

14. Biscaro L, Becatelli A, Poggio PM, et al. The one-model technique: a new method for immediate loading with fixed prostheses in edentuolous or potentially edentulous jaws. Int J Periodontics Restorative Dent 2009;29:306-313.

15. Chaimattayompol N, Stanescu J, Steinberg J, et al. Use of a crossmounting buccal index to help transfer the spatial relationships of an interim prosthesis to the definitive implant-supported prosthesis.
J Prosthet Dent 2001;85(5):509-515. DOI: 10.1067/mpr.2001. 115387.

16. Venezia P, Torsello F, D'amato S, et al. Digital cross-mounting: a new opportunity in prosthetic dentistry. Quintessence Int 2017;48(9):701709. DOI: 10.3290/j.qi.a38863.

17. Joo HS, Park SW, Yun KD, et al. Complete-mouth rehabilitation using a 3D printing technique and the CAD/CAM double scanning method: a clinical report. J Prosthet Dent 2016;116(1):3-7. DOI: 10.1016/j. prosdent.2016.01.007.

18. Carroll WJ, Woelfel JB, Huffman RW. Simple application of anterior jig or leaf gauge in routine clinical practice. J Prosthetic Dent 1988;59(5):611-617. DOI: 10.1016/0022-3913(88)90081-9.

19. Binkley TK, Binkley CJ. A practical approach to full mouth rehabilitation. J Prosthet Dent 1987;57(3):261-267. DOI: 10.1016/0022 3913(87)90293-9.

20. The glossary of prosthodontic terms. J Prosthet Dent. 9th ed., vol. 117(1) 2017. pp. 1-105. DOI: 10.1016/j.prosdent.2016.05.014.

21. Kattadiyil MT, Alzaid AA, Campbell SD. What materials and reproducible techniques may be used in recording centric relation? Best evidence consensus statement. J Prosthodont 2021;30(S1):34-42. DOI: 10.1111/jopr.13321.

22. Hassall D. Centric relation and increasing the occlusal vertical dimension: concepts and clinical techniques - part one. Br Dent J 2021;230(1):17-22. DOI: 10.1038/s41415-020-2502-x.

23. Park DH, Park JM, Choi JW, et al. Accuracy of several implant bite registration techniques: an in-vitro pilot study. J Adv Prosthodont 2017;9(5):341-349. DOI: 10.4047/jap.2017.9.5.341.

24. Wirth CG, Aplin AW. An improved interocclusal record for centric relation. J Prosthet Dent 1971;25(3):279-285. DOI: 10.1016/0022 3913(71)90189-2. 